\title{
Retroperitoneal approach for the treatment of diaphragmatic crus syndrome: technical note
}

\author{
Zach Pennington, BS, ${ }^{1}$ Bowen Jiang, MD, ${ }^{1}$ Erick M. Westbroek, MD, ${ }^{1}$ Ethan Cottrill, MS, ${ }^{1}$ \\ Benjamin Greenberg, MD, ${ }^{2}$ Philippe Gailloud, MD, ${ }^{3}$ Jean-Paul Wolinsky, MD, ${ }^{4}$ Ying Wei Lum, MD, ${ }^{5}$ \\ and Nicholas Theodore, MD ${ }^{1}$
}

\begin{abstract}
'Department of Neurosurgery, Johns Hopkins School of Medicine, Baltimore, Maryland; '2Department of Neurology, University of Texas Southwestern Medical Center, Dallas, Texas; ${ }^{3}$ Division of Interventional Neuroradiology, Johns Hopkins School of Medicine, Baltimore, Maryland; ${ }^{4}$ Department of Neurosurgery, Northwestern University, Chicago, Illinois; and ${ }^{5}$ Department of Vascular Surgery and Endovascular Therapy, Johns Hopkins School of Medicine, Baltimore, Maryland
\end{abstract}

OBJECTIVE Myelopathy selectively involving the lower extremities can occur secondary to spondylotic changes, tumor, vascular malformations, or thoracolumbar cord ischemia. Vascular causes of myelopathy are rarely described. An uncommon etiology within this category is diaphragmatic crus syndrome, in which compression of an intersegmental artery supplying the cord leads to myelopathy. The authors present the operative technique for treating this syndrome, describing their experience with 3 patients treated for acute-onset lower-extremity myelopathy secondary to hypoperfusion of the anterior spinal artery.

METHODS All patients had compression of a lumbar intersegmental artery supplying the cord; the compression was caused by the diaphragmatic crus. Compression of the intersegmental artery was probably producing the patients' symptoms by decreasing blood flow through the artery of Adamkiewicz, causing lumbosacral ischemia.

RESULTS All patients underwent surgery to transect the offending diaphragmatic crus. Each patient experienced substantial symptom improvement, and 2 patients made a full neurological recovery before discharge.

CONCLUSIONS Diaphragmatic crus syndrome is a rare or under-recognized cause of ischemic myelopathy. Patients present with episodic acute-on-chronic lower-extremity paraparesis, gait instability, and numbness. Angiography confirms compression of an intersegmental artery that gives rise to a dominant radiculomedullary artery. Transecting the offending diaphragmatic crus can produce complete resolution of neurological symptoms.

https://thejns.org/doi/abs/10.3171/2020.1.SPINE191455

KEYWORDS diaphragmatic crus syndrome; vascular myelopathy; ventral cord syndrome; anterior spinal artery syndrome; artery of Adamkiewicz; surgical technique

$\mathrm{P}$ ROGRESSIVE spinal cord dysfunction can occur secondary to multiple pathologies, including degenerative compression, neoplastic compression, inflammation (e.g., multiple sclerosis), or vascular etiologies. Within this last category, perhaps the most remarkable example is ventral cord syndrome, also known as anterior spinal artery (ASA) syndrome, which according to Steegmann ${ }^{1}$ was first reported by Preobrashenski in 1904. As originally described, ASA syndrome is characterized by occlusion of the ASA, resulting in ischemia and then infarction of the ventral two-thirds of the spinal cord, which is apparent clinically as a sudden onset of paralysis below the infarct along with loss of pain and temperature sensation. ${ }^{1}$ More broadly, however, we can consider ASA syndrome to be any etiology that decreases blood flow through the ASA. In the cervical spine this may occur secondary to injury of the vertebral artery, ${ }^{2}$ whereas in the thoracic spine this can result from decreased flow through the artery of Adamkiewicz, ${ }^{3-6}$ the dominant radiculomedullary artery supplying the ASA between T8 and L1. ${ }^{7}$

Hypoperfusion through the artery of Adamkiewicz may be caused by multiple etiologies, including induced hypotension, ${ }^{8,9}$ a thromboembolic event, ${ }^{10}$ traumatic tran- 

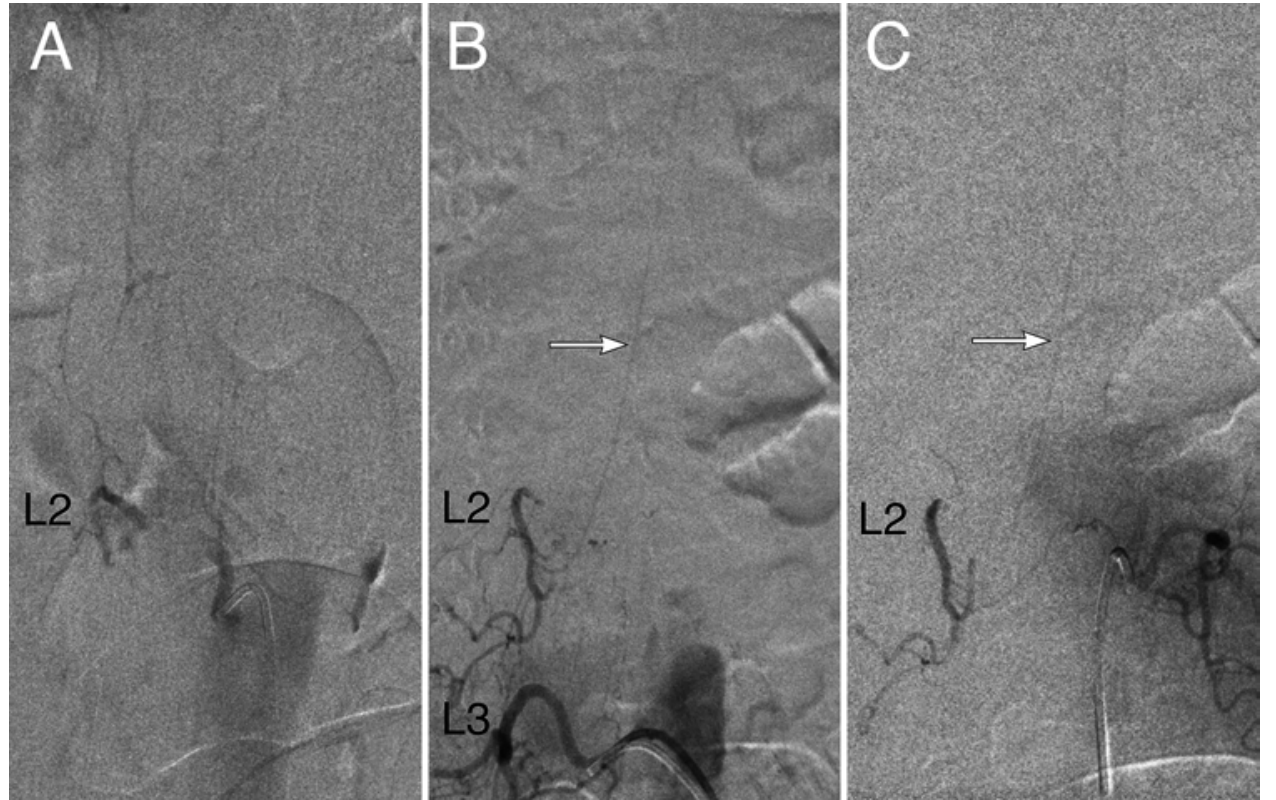

FIG. 1. Case 1. Preoperative angiogram. Injection of the right L2 intersegmental vessel $(\mathbf{A})$ demonstrated a significant opacification defect consistent with compression of the vessel. Injection of the right $L 3$ (B) and left $L 2$ (C) showed partial opacification of the ASA (arrows), consistent with collateral flow through these vessels.

section, ${ }^{4,5}$ or compression. ${ }^{11}$ Compression can be postforaminal/intracanalar, ${ }^{12}$ intraforaminal, ${ }^{11}$ or preforaminal; preforaminal compression generally involves the intersegmental artery giving rise to the artery of Adamkiewicz. We report 3 patients whose lumbar intersegmental arteries were compressed by the diaphragmatic crus, and review the available literature.

\section{Case Reports}

All patients in this series underwent surgery at a single institution. Institutional guidelines required neither patient consent nor institutional review board approval prior to drafting of the present manuscript. All videos, images, and other patient data were de-identified.

\section{Case 1}

\section{History and Examination}

A 74-year-old man presented to an outside hospital with acute-onset paraparesis in the setting of a 10-month progressive myelopathy characterized by paresthesias and numbness of the lower extremities. The patient had previously been found to have hyperintensity within the thoracic cord extending from T7 to T12 on T2-weighted MRI. He was initially treated for transverse myelitis with rituximab and oral corticosteroids, but experienced little improvement. Additional imaging demonstrated negligible stenosis within the thoracolumbar spine and CSF obtained by lumbar puncture was paucicellular, suggesting against an inflammatory pathology. The patient was transferred to another outside institution where, based on his clinical presentation and available imaging, he was diagnosed with spinal ischemia and sent to our center for spinal angiography.
On arrival, the patient reported excruciating low-back and leg pain with frequent back spasms. Physical examination revealed diffuse lower-extremity weakness, a T10 sensory level, and patellar hyperreflexia. Although he was ambulatory, his gait was noticeably myelopathic and he reported urinary incontinence with increasing frequency. Spinal angiography documented compression of the right L2 intersegmental artery by the crus of the diaphragm, with minimal residual flow across the stenotic segment (Fig. 1A). The artery of Adamkiewicz arose from the right L2 but was mostly opacified via collaterals from right L3 and left L2 (Fig. 1B and C). It was concluded that compression of the L2 vessel was causing hypoperfusion of the thoracolumbar cord and was responsible for the patient's clinical symptoms. Transection of the right diaphragmatic crus was recommended.

\section{Operation and Postoperative Course}

Video 1 demonstrates the surgical procedure.

VIDEO 1. Case 1. Intraoperative video demonstrating transection of the diaphragmatic crus and direct decompression of the L2 intersegmental vessel. Copyright Nicholas Theodore. Published with permission. Click here to view.

The patient was placed supine on a standard operating room table. A midline laparotomy incision was performed and a transperitoneal approach adopted. Malleable retractor blades were affixed to an abdominal ring retractor and used to maintain the surgical corridor. The small bowel with the duodenum was mobilized laterally after freeing up the ligament of Treitz. The retroperitoneum was then dissected to expose the medial surface of the aorta. The inferior mesenteric artery was identified and preserved. The dissection was then carried down to the aortocaval window and the L3 intersegmental artery identified; the 
dissection was then carried up superiorly until the L2 intersegmental artery was identified. The L2 vessel was hypotrophic secondary to compression by the right diaphragmatic crus.

An operative microscope with an 801-nm filter for detection of indocyanine green (ICG) fluorescence was brought into the field. ICG angiography demonstrated significant stenosis at the point where the vessel descended posterior to the diaphragmatic crus. To relieve the compression, the crus was sharply transected using Metzenbaum scissors, after which the pulse in the L2 intersegmental vessel improved dramatically. A portion of the medial right psoas muscle was also resected along the course of the L2 vessel, providing additional decompression. ICG angiography confirmed adequate decompression. After ensuring that hemostasis had been achieved, the retroperitoneum was closed with 2-0 braided polyglactin 910 . The abdominal wall was closed with looped No. 1 polydioxanone suture in the fascial layer, 2-0 and 3-0 polyglactin 910 in the subcutaneous tissue, and a 4-0 synthetic polyester monofilament in the dermis. The patient emerged from anesthesia without issue and was neurologically intact on examination. The postoperative course was uneventful, and he was discharged on postoperative day 14 to inpatient rehabilitation because of his significant baseline weakness. Postoperative angiography demonstrated restoration of flow through the right L2 intersegmental vessel (Fig. 2). At 6-week follow-up, the patient was ambulatory with significant improvement of his baseline weakness, pain, and spasms.

\section{Case 2}

\section{History and Examination}

A 42-year-old man was referred to our center with acute-onset, left-sided abdominal pain with paresis, numbness, and paresthesias in both legs. MRI demonstrated increased T2 signal in the distal thoracic cord, initially thought to be consistent with transverse myelitis. On further evaluation, however, acute spinal cord ischemia was suspected and spinal angiography was obtained. Angiography documented compression of the left L1 intersegmental artery, which gave rise to the artery of Adamkiewicz by the diaphragmatic crus.

\section{Operation and Postoperative Course}

The patient was placed in the lateral decubitus position and a retropleural approach was adopted after incision at the level of the 11th rib. The proximal rib was resected to facilitate access to the prevertebral space at the T12/ L1 level. The left psoas muscle was mobilized from the T12 and L1 vertebral bodies to expose the intersegmental vessels and to allow identification of the diaphragmatic crus. The left crus was transected to decompress the L1 intersegmental artery, as confirmed by intraoperative angiography. However, focal thrombosis was noted within the left L1 vessel, in which thrombolysis was performed using tissue plasminogen activator. The patient had fully recovered strength in his lower extremities by the time of his discharge on postoperative day 5. As of the 14-month follow-up, he had experienced no symptom recurrence.

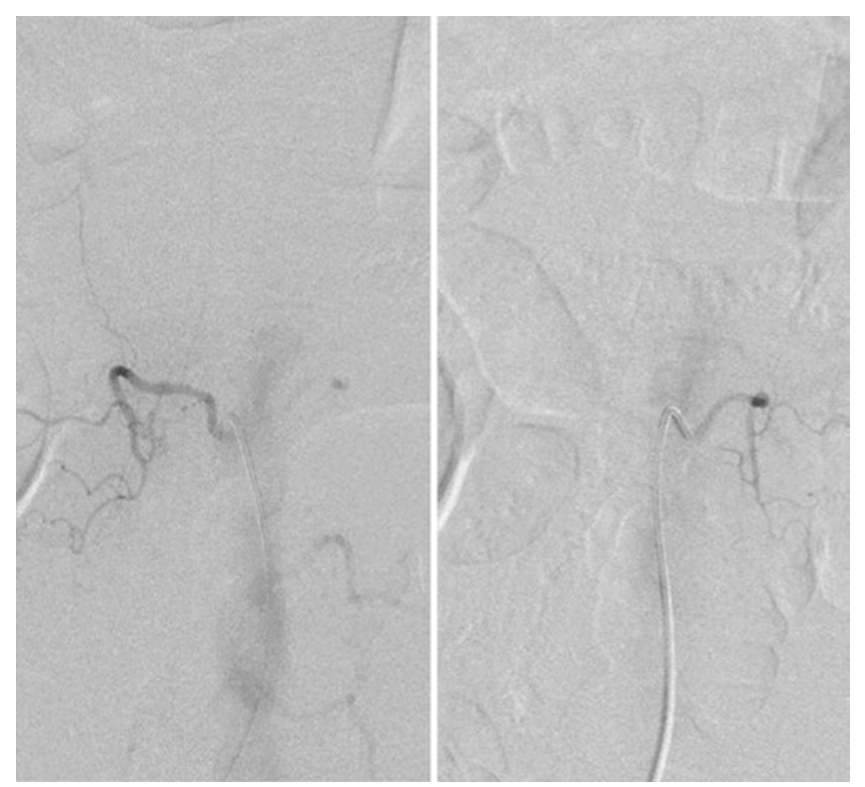

FIG. 2. Case 1. Postoperative angiogram. Left: Injection of the right L2 intersegmental vessel demonstrates no significant flow void, indicating a relief of preoperative compression by the right diaphragmatic crus. Right: As a control, injection of the left L2 intersegmental vessel demonstrated no significant change in flow.

\section{Case 3}

History and Examination

A 66-year-old man presented with acute bilateral weakness of the lower extremities, as well as pain and weakness of the left upper extremity. The patient was admitted with concern for an acute inflammatory process, such as Guillain-Barré syndrome or transverse myelitis. Cerebrospinal T2-weighted MRI documented hyperintensity at the conus medullaris level, whereas results of MR angiography were unremarkable. Lumbar puncture revealed paucicellular CSF inconsistent with inflammation. Spinal angiography demonstrated compression of the right L2 intersegmental artery, which supplied the artery of Adamkiewicz, by the diaphragmatic crus. The compression was thought to be responsible for the lower-extremity symptoms and the decision was made to decompress the vessel.

\section{Operation and Postoperative Course}

The patient was treated via a retroperitoneal approach after placement in the lateral decubitus position. The surgical incision was made halfway between the T12 rib and iliac crest, and a corridor was formed in the retroperitoneal space to expose the lumbar vertebrae. Counting up from the L3/4 level, the L2 intersegmental artery was identified; the crus was sharply divided with Metzenbaum scissors and bipolar coagulation. Intraoperative angiography confirmed decompression of the L2 intersegmental artery. The patient remained stable in the immediate postoperative period, and showed substantial improvement of bilateral lower-extremity strength at 2-month follow-up. At 20 months he had almost completely recovered his lowerextremity strength, with only residual weakness observed in his left iliopsoas. 
TABLE 1. Reported cases of ventral cord syndrome secondary to intersegmental artery compression by the diaphragmatic crus

\begin{tabular}{|c|c|c|c|c|}
\hline $\begin{array}{l}\text { Authors } \\
\& \text { Year }\end{array}$ & $\begin{array}{l}\text { Age in } \\
\text { Yrs/Sex }\end{array}$ & Vessel & Presentation & Treatment/Postop Course \\
\hline \multirow[t]{2}{*}{$\begin{array}{l}\text { Rogopoulos } \\
\text { et al., } \\
2000^{17}\end{array}$} & $60 / \mathrm{M}$ & Rt L2 & $\begin{array}{l}\text { - Recurrent paraplegia w/ extension of BLE (duration } 30 \\
\text { mins-2 hrs) }\end{array}$ & $\begin{array}{l}\text { - Sectioning of rt crus } \\
\text { - Complete resolution by POD } 1 \\
\text { - No recurrence as of 7-yr FU }\end{array}$ \\
\hline & $42 / M$ & Rt L2 & $\begin{array}{l}\text { - Repeat episodes of acute-onset BLE paraplegia w/ pain fol- } \\
\text { lowed by spontaneous resolution ( } 30 \text { mins-4 hrs duration) }\end{array}$ & $\begin{array}{l}\text { - Sectioning of rt crus } \\
\text { - No recurrence of symptoms as of 4-yr FU }\end{array}$ \\
\hline $\begin{array}{l}\text { Batt et al., } \\
2008^{13^{*}}\end{array}$ & $44 / \mathrm{M}$ & Rt L2 & • Recurrent, transient paraplegia in supine position & $\begin{array}{l}\text { - Sectioning of rt crus } \\
\text { - No recurrence as of 1-yr FU }\end{array}$ \\
\hline $\begin{array}{l}\text { Lagarde et } \\
\quad \text { al., } 2011^{15}\end{array}$ & $57 / \mathrm{M}$ & Rt L2 & $\begin{array}{l}\text { - Recurrent pelvic pain, dysuria, BLE paresis w/ exertion } \\
\text { - Acute-onset BLE flaccid paraplegia, hyporeflexia, numbness }\end{array}$ & $\begin{array}{l}\text { - No treatment } \\
\text { - Substantial recovery w/ PT by } 6 \text {-mo FU after } \\
\text { acute event }\end{array}$ \\
\hline \multirow[t]{2}{*}{$\begin{array}{l}\text { Gailloud } \\
\text { et al., } \\
2015^{14}\end{array}$} & $<13 / ?$ & Rt T12 & $\begin{array}{l}\text { - Acute-onset BLE paraplegia, bladder incontinence } \\
\text { - New-onset T2 hyperintensity of conus } \\
\text { - Failure of immunoglobulin G treatment }\end{array}$ & - No treatment or clinical FU reported \\
\hline & ?/F & Lt L1 & $\begin{array}{l}\text { - Acute-onset bowel/bladder dysfunction w/ BLE numbness } \\
\text { - T2 hyperintensity of conus } \\
\text { - Failure of corticosteroids \& plasmapheresis }\end{array}$ & - No treatment or clinical FU reported \\
\hline $\begin{array}{l}\text { Orru' et al., } \\
2017^{16} \dagger\end{array}$ & $42 / \mathrm{M}$ & Lt L1 & $\begin{array}{l}\text { - Acute-onset paraplegia, BLE numbness, \& bowel/bladder } \\
\text { dysfunction } \\
\text { - Progressive myelomalacia of conus on serial MRI }\end{array}$ & $\begin{array}{l}\text { - Sectioning of It crus } \\
\text { - Postop angiogram demonstrates thrombosis of } \\
\text { It L1 vessel, recanalized w/ nicardipine \& tPA } \\
\text { - Complete resolution of symptoms } \\
\text { - No recurrence as of } 14-m o \text { FU }\end{array}$ \\
\hline \multirow[t]{2}{*}{$\begin{array}{l}\text { Present } \\
\text { study }\end{array}$} & $74 / \mathrm{M}$ & Rt L2 & $\begin{array}{l}\text { - Progressive acute-on-chronic BLE weakness, paresthesias, } \\
\text { \& gait abnormality; T10 sensory level }\end{array}$ & $\begin{array}{l}\text { - Sectioning of rt crus } \\
\text { - Complete resolution of weakness by POD } 1\end{array}$ \\
\hline & $66 / M$ & Rt L2 & • Acute-onset It > rt LE weakness; T12 sensory level & $\begin{array}{l}\text { - Sectioning of rt crus } \\
\text { - Substantial improvement in symptoms by 2-mo } \\
\text { FU \& near complete resolution by } 20 \text {-mo FU }\end{array}$ \\
\hline
\end{tabular}

$\mathrm{BLE}=$ bilateral lower extremity; FU = follow-up; $\mathrm{LE}=$ lower extremity; $\mathrm{POD}=$ postoperative day; $\mathrm{PT}$ = physical therapy; $\mathrm{tPA}$ = tissue plasminogen activator.

* Two of the 3 cases presented by Batt et al. were previously reported by Rogopoulos et al.

† Case 4 reported by Orru' et al. is reported as case 2 here; information about neurological follow-up is also provided.

\section{Discussion}

The anterior two-thirds of the spinal cord are perfused by the ASA, which is supplied by several radiculomedullary contributions at the cervical, thoracic, and lumbar levels. The dominant contribution is usually provided at the thoracolumbar level by the artery of Adamkiewicz. Occlusion,,$^{10}$ transection,, 45 or compression ${ }^{11}$ of this artery may result in decreased blood flow to the ASA and subsequent infarction of the spinal cord. Compression of the artery of Adamkiewicz can be postforaminal/intracanalar, ${ }^{12}$ intraforaminal, ${ }^{11}$ or preforaminal-the latter generally involving the parent intersegmental artery, notably as it passes through or beneath the diaphragmatic crus.

\section{Workup}

Reports of ventral cord syndrome secondary to intersegmental artery compression by the diaphragmatic crus are rare, with only 7 cases reported in the literature (Table 1). ${ }^{13-17}$ The typical clinical presentation is acute-onset myelopathy. Patients initially present with symptoms consistent with compressive myelopathy, including paresis or paresthesias of the lower extremities, gait abnormalities, hyperreflexia, and incontinence. This results from hypo- perfusion of the ascending anterolateral tracts and ventral horns of the spinal gray matter, which carry ascending nociceptive and thermoreceptive inputs, and contain the bodies of $\alpha$ motor neurons, respectively. These $\alpha$ motor neurons innervate the somatic musculature, and their ischemic injury leads to rapid paraparesis or paraplegia.

Given the similarity in presentation to spinal cord compression syndrome (e.g., conus medullaris syndrome), initial workup of ventral cord syndrome generally includes MRI, which demonstrates a patent canal and hyperintensities within the thoracolumbar spinal cord on T2-weighted imaging-concerning for an inflammatory etiology., ${ }^{3,14,16}$ The lack of improvement with antiinflammatory medications or intravenous immunoglobulin and the often episodic nature of ventral cord syndrome must raise the suspicion of a vascular etiology. Spinal angiography is essential in identifying the compressed intersegmental artery and confirming that it participates in the supply of the spinal cord. The involved branch was the right L2 intersegmental artery in 6 of the 9 reported cases, including 2 cases in the present series (our case 2 was reported by Orru' et al.; see Table 1). ${ }^{13-17}$ Once the point of compression by the diaphragmatic crus has been identified, a midline laparotomy and transperitoneal approach can be 
used to transect the implicated diaphragmatic attachment. Successful relief of the compression led to complete resolution of symptoms in 5 of the 6 cases in which surgical treatment was reported. ${ }^{13,17}$ The sixth case does not include follow-up information, and it is unclear whether surgical correction provided clinical benefit for that patient.

\section{Hypothesis for the Etiology of the Syndrome}

Predominant involvement of upper lumbar intersegmental arteries (right L2 in particular) is consistent with classic anatomical data. ${ }^{18}$ As the aorta descends through the aortal hiatus, it remains relegated to the left anterolateral face of the vertebral body. It is thus possible that the longer course of right-sided intersegmental arteries offers a greater risk for compression by the anteriorly placed diaphragmatic crura. Additionally, the right diaphragmatic crus is thicker than the left crus, increasing the magnitude of the compressive force applied to underlying vessels. ${ }^{13}$ Last, although both the L1 and L2 intersegmental arteries lie between the diaphragmatic crus and the vertebral column, the available space at the L2 level is much smaller, because the fibers of the crus begin to integrate with the anterior longitudinal ligament at this level. Lower lumbar intersegmental arteries are caudal to the enthesis of the diaphragm and cannot be compressed by this mechanism.

Despite the direct role posited for a compressive etiology, it is likely that other comorbidities help dictate whether a patient becomes symptomatic. In the identified cases, we noted that nearly all were in the second half of their lives and had one or more risk factors for peripheral vascular disease, including diabetes mellitus, hypertension, or dyslipidemia. ${ }^{19}$ We posit, therefore, that these patients may have had greater degeneration of their arteries, including those feeding the artery of Adamkiewicz. In this setting, compression of the dominant vessel would result in hypoperfusion of the ASA and the onset of the patient's symptoms.

Given this proposed pathophysiology, it is clear that sectioning the implicated diaphragmatic crus can alleviate the extrinsic compression and resolve the stenosis. Accordingly, as supported by the literature, patients may experience a cessation of their acute myelopathic episodes and, where there has been no permanent cord infarct, complete resolution of their neurological symptoms.

\section{Limitations of the Study}

The present study is a technical note based on our experience with 3 patients and is consequently limited in its ability to provide generalizable results. However, it is noted that identical treatment in the literature has mitigated similarly profound improvement in patients' clinical picture.

\section{Conclusions}

We report 3 cases of diaphragmatic crus syndrome and also provide an operative video illustrating the surgical treatment in one of these patients. The present outcomes, along with the results compiled from a review of the available literature, suggest that sectioning the implicated diaphragmatic crus can produce robust improvement in neurological status and complete resolution of the myelopathy.

\section{References}

1. Steegmann AT. Syndrome of the anterior spinal artery. Neurology. 1952;2(1):15-35.

2. Montalvo M, Bayer A, Azher I, et al. Spinal cord infarction because of spontaneous vertebral artery dissection. Stroke. 2018;49(11):e314-e317.

3. Gao Z, Zhao K, Pan H, et al. Spinal cord ischemia after endovascular aortic repair of a unilateral iliac artery dissecting aneurysm: a case report. Ann Vasc Surg. 2019;59:306. e1-306.e5.

4. Phillips D, Dhall SS, Uzelac A, Talbott JF. Gunshot wound causing anterior spinal cord infarction due to injury to the artery of Adamkiewicz. Spine J. 2016;16(9):e603-e604.

5. Rogers FB, Osler TM, Shackford SR, Wald SL. Isolated stab wound to the artery of Adamkiewicz: case report and review of the literature. J Trauma. 1997;43(3):549-551.

6. Yamauchi T, Kubota S, Hasegawa K. Delayed paraplegia triggered by gastrointestinal bleeding 8 months after TEVAR: persistent vulnerability of spinal cord. Ann Vasc Dis. 2018;11(4):562-564.

7. Taterra D, Skinningsrud B, Pękala PA, et al. Artery of Adamkiewicz: a meta-analysis of anatomical characteristics. Neuroradiology. 2019;61(8):869-880.

8. Drummond JC, Lee RR, Owens EL. Spinal cord ischemia occurring in association with induced hypotension for colonic surgery. Anesth Analg. 2012;114(6):1297-1300.

9. Singh U, Silver JR, Welply NC. Hypotensive infarction of the spinal cord. Paraplegia. 1994;32(5):314-322.

10. Tanaka H, Minatoya K, Matsuda H, et al. Embolism is emerging as a major cause of spinal cord injury after descending and thoracoabdominal aortic repair with a contemporary approach: magnetic resonance findings of spinal cord injury. Interact Cardiovasc Thorac Surg. 2014;19(2):205210.

11. Ram S, Osman A, Cassar-Pullicino VN, et al. Spinal cord infarction secondary to intervertebral foraminal disease. Spinal Cord. 2004;42(8):481-484.

12. Reynolds JM, Belvadi YS, Kane AG, Poulopoulos M. Thoracic disc herniation leads to anterior spinal artery syndrome demonstrated by diffusion-weighted magnetic resonance imaging (DWI): a case report and literature review. Spine J. 2014;14(6):e17-e22.

13. Batt M, Rogopoulos A, Benchimol D, et al. Paraplegia with lumbar artery compression by the diaphragmatic crus. $J$ Vasc Surg. 2008;48(4):1017-1021.

14. Gailloud P, Gregg L, Galan P, et al. Periconal arterial anastomotic circle and posterior lumbosacral watershed zone of the spinal cord. J Neurointerv Surg. 2015;7(11):848-853.

15. Lagarde J, Hainque E, Biondi A, et al. Spinal cord infarction due to compression of a lumbar artery by the right diaphragmatic crus [in French]. Rev Neurol (Paris). 2011;167(67):551-553.

16. Orru' E, Sorte DE, Wolinsky J-P, et al. Intraoperative spinal digital subtraction angiography: indications, technique, safety, and clinical impact. J Neurointerv Surg. 2017;9(6):601607.

17. Rogopoulos A, Benchimol D, Paquis P, et al. Lumbar artery compression by the diaphragmatic crus: a new etiology for spinal cord ischemia. Ann Neurol. 2000;48(2):261-264.

18. Ratcliffe JF. Microarteriography of the cadaveric human lumbar spine. Evaluation of a new technique of injection in the anastomotic arterial system. Acta Radiol Diagn (Stockh). 1978;19(4):656-668.

19. Shu J, Santulli G. Update on peripheral artery disease: 
epidemiology and evidence-based facts. Atherosclerosis. 2018;275:379-381.

\section{Disclosures}

Dr. Jiang is a consultant for Longeviti Neuro Solutions, and receives grant funding from DePuy Synthes. Dr. Gailloud is a consultant for Cerenovus, and he receives an unrelated research grant from Siemens Medical. Dr. Wolinsky is a consultant for AO Foundation, Siemens, and Icotec. Dr. Theodore receives royalties and has an ownership interest in Globus Medical, and he is a consultant for Globus Medical and DePuy-Synthes.

\section{Author Contributions}

Conception and design: Theodore, Wolinsky, Lum. Acquisition of data: Pennington, Westbroek, Greenberg. Analysis and interpreta- tion of data: Theodore, Pennington, Jiang. Drafting the article: Pennington, Jiang. Critically revising the article: all authors.

Reviewed submitted version of manuscript: all authors. Administrative/technical/material support: Theodore. Study supervision: Theodore.

\section{Supplemental Information}

Videos

Video 1. https://vimeo.com/387956885.

\section{Correspondence}

Nicholas Theodore: Johns Hopkins School of Medicine, Baltimore,MD. theodore@jhmi.edu. 